\title{
Application of Robots and Robotic Systems in Agriculture
}

\author{
Domagoj Zimmer*, Ivan Plaščak, Željko Barač, Mladen Jurišić, Dorijan Radočaj
}

\begin{abstract}
The paper depicts agricultural robots that can perform complex tasks. Fast development and application of agricultural robotics is a result of increased development of agricultural machinery. Robots are complex and intelligent systems with a significant role in agriculture that are becoming an integral part of both the technological and scientific progress. The paper presents some important roles of robots and robotic systems in various agricultural areas and explains the deployment of new technologies supported by the examples of their application in arable farming, horticulture, and forestry. Robotics application decreases the deployment of human resources, enables significant production cost savings, and increases production capacity. The application of robotic systems facilitates high precision levels and repetition speed regarding time and space, which cannot be replicated by farmers.
\end{abstract}

Keywords: agriculture; robotic systems; robots; sensors

\section{INTRODUCTION}

A robot usually involves an electromechanical machine that can move, perform operations using a limb joint, feel external stimuli, and physically affect its environment [1]. The application of robotics in agriculture has resulted in an increased application of automated guided robots that minimize production losses [2]. The author argues that soon cooperative teams consisting of small autonomous agricultural robots are bound to be present in agricultural fields. During the last twenty years, the integration of many autonomous vehicles, especially agricultural robots, has been enabled based on the application of specialized sensors. Machine vision, global positioning systems - GPS, real-time kinematics, laser-based equipment, and inertial devices, actuators (hydraulic cylinder, linear and rotary electrical motors), and electronic equipment (built-in computers, industrial PC and PLC) are components of new robots in agriculuture [3-7]. The authors [8] claim that robotics improves common agricultural practices, such as yield increase, and reduces the application of environmentally hazardous chemicals. Additionally, new agricultural robotic systems are being developed to facilitate integration of different technologies as well as modularity, flexibility, and adaptability. Robotics is a new scientific and technological dimension. The progress of technology and science accompanied by the development of artificial intelligence as one of the most important factors has qualified robots to become intelligent working partners [9].

A robot is an electromechanical movable device designed to perform tasks using its axes, feel external stimuli, and to physically affect its environment [10]. Artificial intelligence and robotics have been increasingly used to perform tasks in specific workspace concepts with robots becoming increasingly humanoid (like human beings with arms and legs, a head with eyes, as well as with 'skin') [11]. The authors [12] claim that robotics integrates mechanics, electronics, computer science, information systems, and automation. Automation studies the principles and theory of automatic control systems as well as the devices that perform tasks without continuous human control.
As stated by the authors [13] the basic division of robots is the division according to the degree of independence, into industrial and autonomous mobile robots

Agricultural robots can be autonomous or semiautonomous systems able to move through different process phases to solve complex problems. They have been successfully implemented in repetitive tasks to reduce human workload and to optimize time and cost regarding soil preparation [13], irrigation, plant protection [14-17], pruning [18], harvesting [19-22], surveillance and control [23-28], and mapping [29]. According to [30], after only a year, the introduction of robots in production processes was justified both productionally and financially. According to [31-34], automatization resulted in increased productivity of agricultural machinery arising from a higher level of efficiency, reliability and precision, and a reduction of human intervention.

Based on the structural features of objects and the environment, the authors [35] distinguish four groups of robots: 1) both the environment and objects are structured; 2 ) the environment is structured, whereas the objects are unstructured; 3 ) the environment is structured, whereas the objects are unstructured; 4) both the environment and the objects are unstructured. The domain of agriculture relates to the fourth group in which neither the environment nor the objects are structured, which poses a challenge regarding commercialization. The agricultural environment requires robots to be mobile compared to most robots used in factories or parked vehicles, whose mobility is limited. Authors [36] in their research state that a robotic system must be costeffective, while at the same time safe and reliable for human safety, environmental protection, and crops.

The author [37] claim how robots also have their disadvantages: robots reduce the chances of employment in the industries, human labor is no longer required in farms. Robots can handle their prescribed tasks, but they can't handle unexpected situations. Robots can be a danger, this is because no one can trust a robot as it does not have a human brain that can think before doing anything, what ever is fed to the robots through chips is performed if it goes wrong. Once the machine damages, the whole farm can come into 
chaos. A high cost is needed to train employees with robots, if the robots are ruling the work in many places, the labor is needed to assist them, because the whole work can't be thrown in the ability of the robots, So, the employees need training and that involves cost, So, a lot of money is involved with the installation of machines in the workplace.

\section{ROBOTIC OPERATING PRINCIPLES}

Robots work on the principle of mobility and sensor data collection (Fig. 1) [38]. Robot mobility is controlled by a remote-control device, which is an RF data encoding emitter. The remote- control consists of a keypad connected to the 8bit microcontroller AT89C2051. The emitter transmits the data produced by the microcontroller. The RF receiver microcontroller 89C51 is built in the robot and it decodes the data sent by the remote-control. The whole robot is powered by a battery that produces $+5 \mathrm{~V}$ of voltage for the microcontroller, and $+12 \mathrm{~V}$ of cranking voltage [39].

A robot consists of DC motors that enable its mobility and an RF data receiver. To move smoothly, a robot requires sensors and controls, which manage its movement in unknown surroundings. It usually consists of five main parts: sensors, a controller/computer, a drive/actuator (transducer), a robotic arm, and an end-effector $[40,41]$.

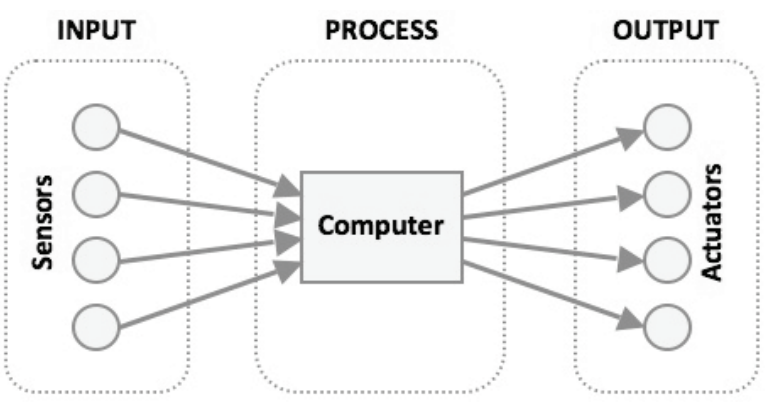

Figure 1 The principle of operation of the robot (Source: Nepalla Choudary)

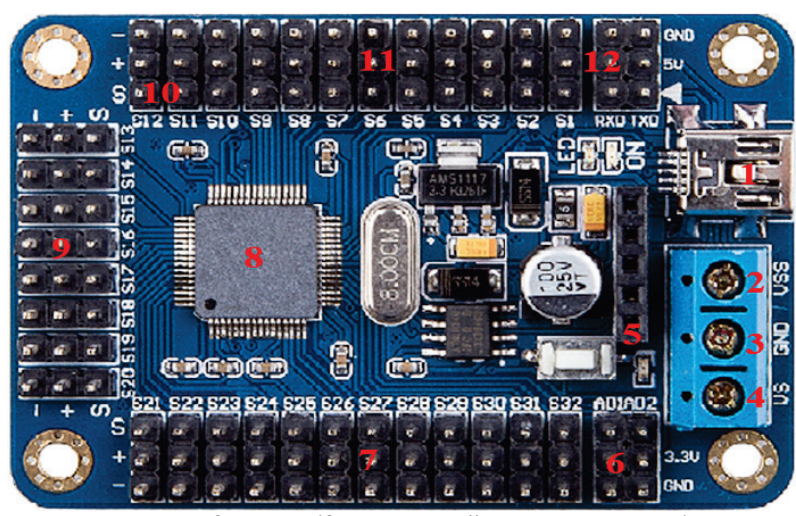

Figure 2 Controller (Source: https://www.elabpeers.com) (1-mini USB, 2-chip VCC, 3-GND, 4-servo VCC, 5-WIFI, 6-AD input, 7-channel 21-31 servo motor, 8-CPU 32 bit, 9-channel 13-20 servo motor, 10-servo controlling signal, 11-channel 1-12 servo motor, 12-UART)

Sensors send data in the format of electronic signals back to the controller. They provide the robot controller with the data from the environment. The most often built-in sensors in robots are the following: a microphone, an ultrasound

sensor, an acoustic vector sensor, a camera, an infrared sensor, and a sensor for detection of specific chemicals. Robots can be transformed and programmed so that the collected data surpass the five human senses. A controller or computer, which is a term found in common use, is the robot's brain. It supports the connection between a robot and other systems so that it can cooperate with other devices, processes, or robots (Fig. 2).

An actuator is a mechanical device that produces motion. There are different types of actuators and the most often used are a hydraulic, pneumatic, DC, and servomotor as well as a stepper (Fig. 3).

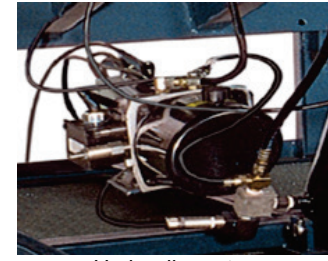

Hydraulic motor

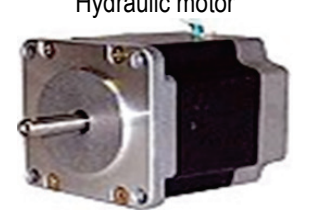

Stepper motor

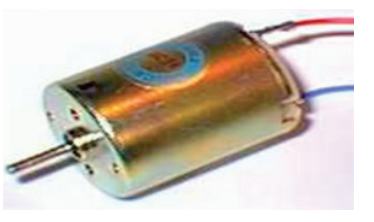

DC Motor

Figure 3 Actuators (Source: N.Nagarjuna Reddy)

Pneumatic cylinder

Servo motor
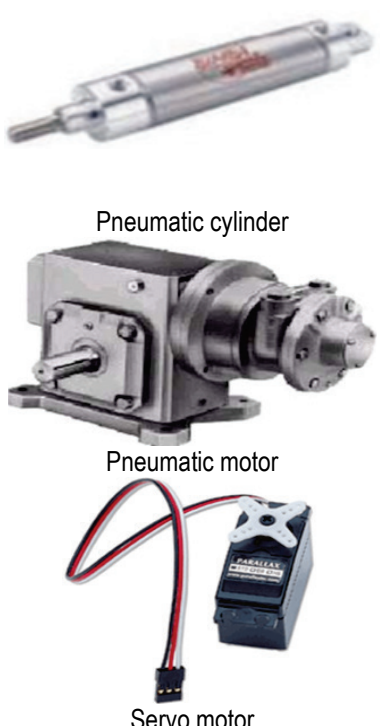

An agrobot consists of a DC motor with an H-bridge electronic circuit that enables a change of the voltage polarity. The installation of the H-bridge results in forward and backward locomotion of the DC motor through the connection and disconnection of the S1-S4 assembly (Fig. 4). A robotic arm is a robot part that sets the end effectors and sensors to perform the tasks programmed in advance. The robotic arm looks like a human arm and it has a shoulder, an elbow, a joint, and fingers. The end effectors are the robot's last link (i.e., the end) of the robot.

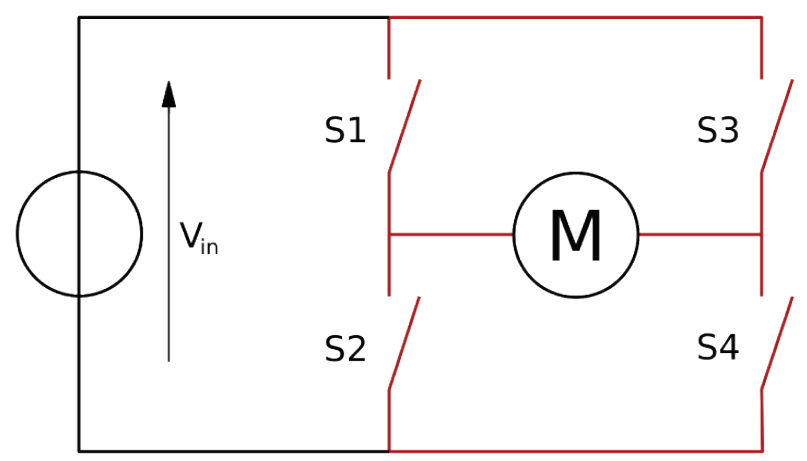

Figure 4 Structure of an $\mathrm{H}$ bridge (Source: http://eleccomponentz.blogspot.com) 
Tools are attached to this endpoint. In a wider sense, the end-effectors can be considered a robotic part that affects the working environment. As agricultural production is concerned, the most often used effectors are a pincher (Fig. 5) which is used in research [42] and a vacuum pump (Fig. 6).
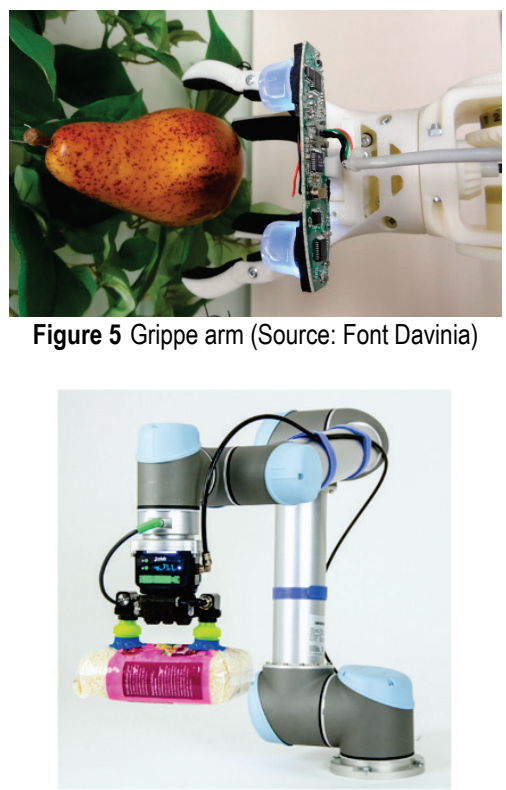

Figure 6 Vacuum pump

(Source: https://www.therobotreport.com)

Robots are increasingly used in agriculture for pest control, where it is necessary to perform plant protection following specific safety rules regarding the human operator. A robot named Agrobot was constructed for the research of authors [43] to protect crops and farmers' health. Agrobot is a remotely controlled robot used for the application of protective chemicals both indoors and outdoors (Fig. 7).

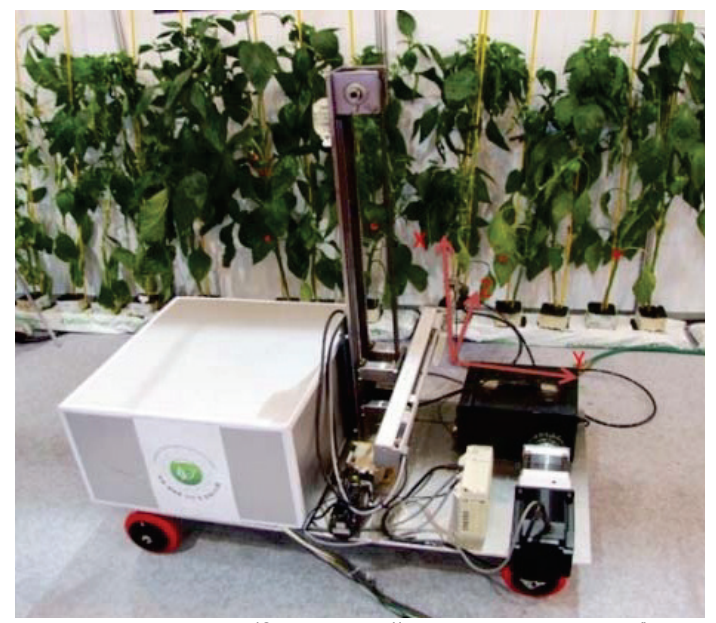

Figure 7 Agrobot (Source: http://robotics.ee.pusan.ac.kr/)

It consists of a keypad, a microcontroller, a battery, DC motors, an RF receiver, a pneumatic compressor, a container for air and protective chemicals, wheels, and a frame. The block diagram shows its working principle (Fig. 8) [44].

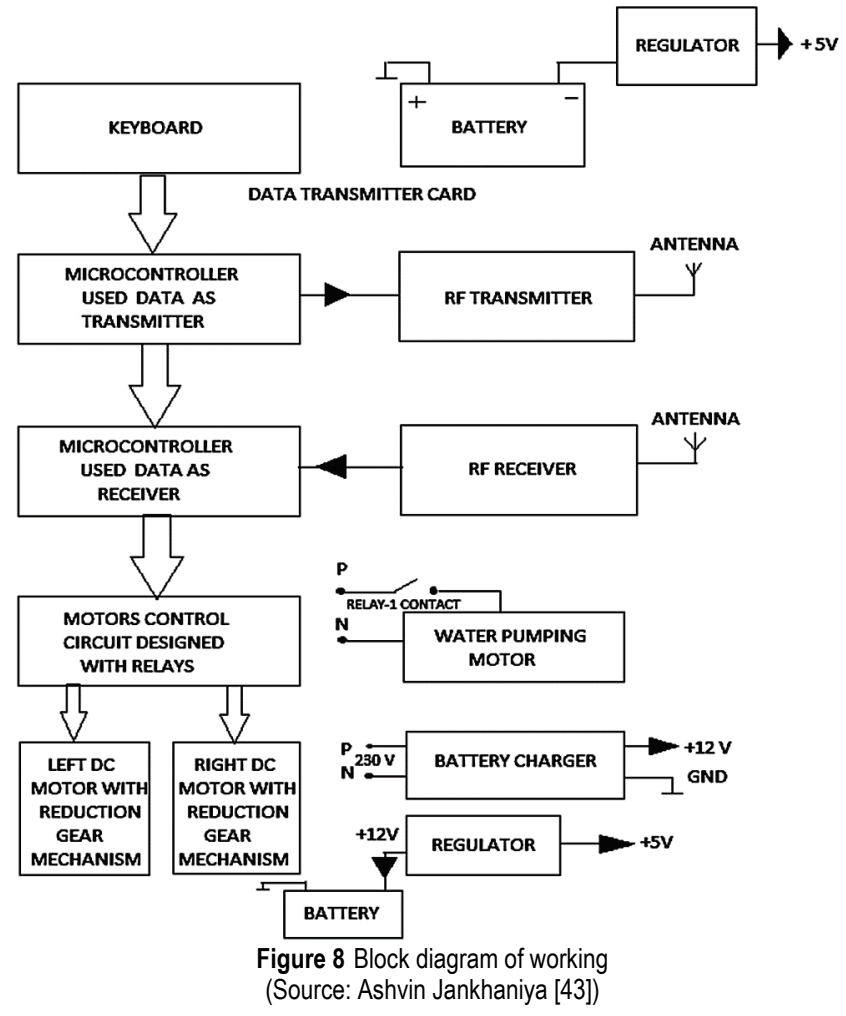

\section{ROBOTIC SYSTEMS}

Robots and robotics have facilitated the introduction of 'farms of the future', where robots perform difficult tasks once done by people (Fig. 9). Robots have been increasingly used in plant protection due to their ability to exclusively target the area affected by pest or illness, instead of the whole area. Apart from agriculture, robots have been used in forestry, protected areas, and horticulture, in which areas the use of the robotic arm is significant (Fig. 10). The robot known as Demeter has been increasingly used for harvesting. It has two cameras that can distinguish between the ripe crop and other plants. Additionally, it can drive, manage, and manipulate the harvester head allowing the driver to focus on other tasks. Finally, its major advantage is a high accuracy of 3 centimetres.

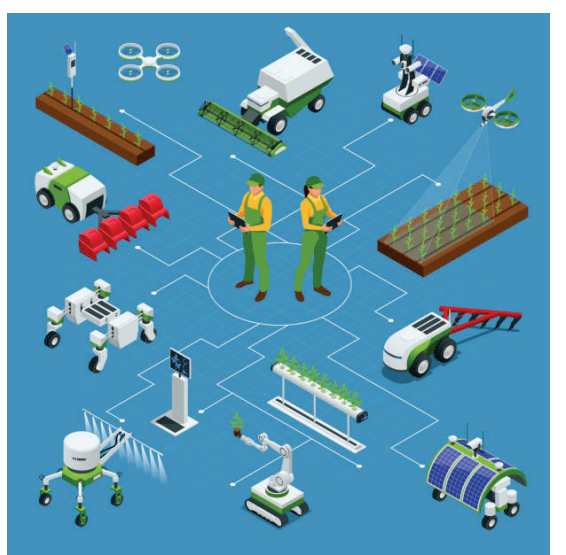

Figure 9 Future farms (Source: https://www.istockphoto.com [45]) 
Furthermore, weed detecting and removing robot has been widely applied. A four-wheel drive weed detecting robot was developed by the Danish Centre for Economic and Business Research. The purpose of the weeding device is to remove and destroy weed. An intelligent 'hoe' uses the vision system to detect crop rows by positioning itself precisely between them, which decreases the use of herbicides. The process itself is based on colour photography. The robot can destroy weed promptly by determining the position and the level of weed development in crops. Contactless methods have been increasingly used including laser treatments and micro sprayers, which deploy machine vision and nozzles.

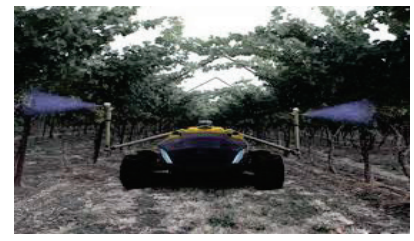

Robotic spraying

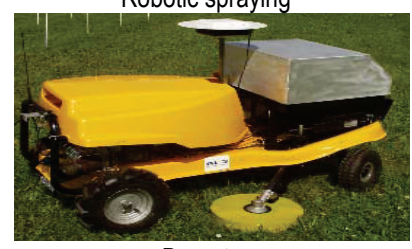

Demeter

Figure 10 Robot types (Source: N.Nagarjuna Reddy)

Arm pick-up

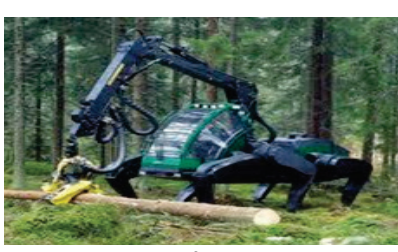

Robot forester

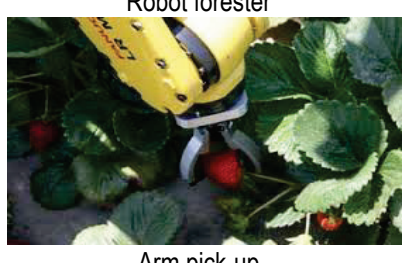

$A R A$ robot is a Swiss robot that with the help of artificial intelligence and solar drive (Fig. 11) can move independently through the field, detect weeds and then target it, with less use of herbicides and thus reduce the total use of herbicides by as much as 20 times on an area of 7.5 hectares per day. The Ara robot moves independently through the field with the help of a camera, GPS sensor, and a solar drive that allows it 12 hours of independent work. It covers the ground only by placing bearings and positioning with the help of a camera, GPS RTK, and sensors. Vision system allows to track crop rows and detect the presence and position of weeds in and between rows. Two robotic arms then apply a microdose of herbicide, systematically targeting the detected weeds [47].

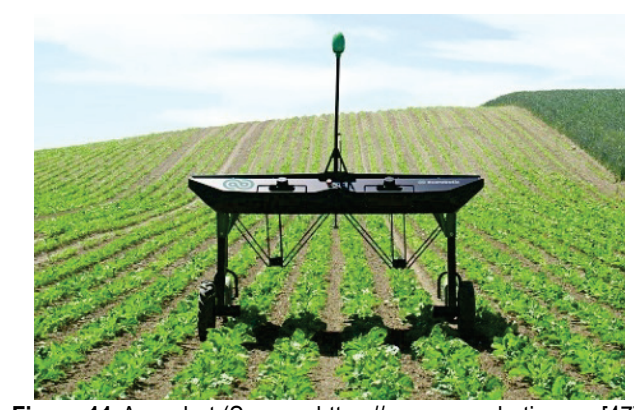

Figure 11 Ara robot (Source: https://www.ecorobotix.com [47])

Apart from robots, a robotic suit has been of great help in agriculture. This latest technology connects the man to a robotic system, i.e., the man wears the suit. The robotic suit is designed for difficult agricultural tasks, such as frequent harvesting of radish. The suit has eight motors set across shoulders, elbows, back, and knees to provide the carrier with more strength. The current model weighs 26 kilograms (Fig. 12).

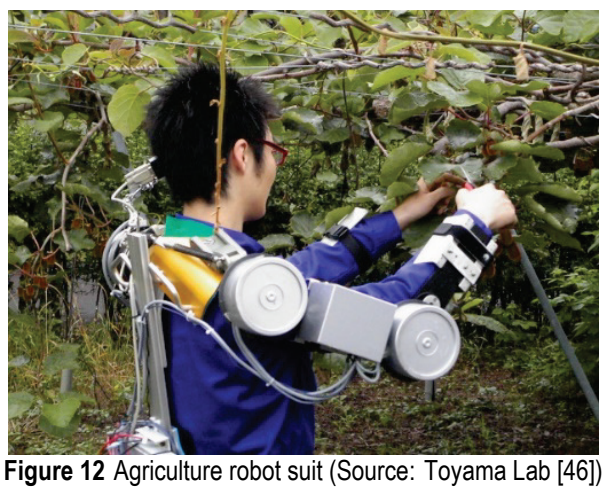

Robots substitute human labour and ensure a fast return on investment. They are increasingly useful in situations that present health and safety hazards. The research [48] cites that robotic systems must be both economically efficient as well as safe and reliable regarding people, environment, and crops. The authors [49] argue that robot application decreases human labour and increases productivity. Additionally, it decreases yield loss. It is of special importance that in cases when robots use certain programmes to create practical recommendations or when they perform specific agricultural tasks, the level of environmental protection and human safety increases.

In Frence was invented the first autonomous electric weed control robot powered by commercial farms. The $\mathrm{Oz}$ robot (Fig. 13) is designed for application in small gardens, Dino (Fig. 14) is used for large vegetable crops, and Ted (Fig. 15) for vineyards and orchards and can cover up to 10 acres per day.

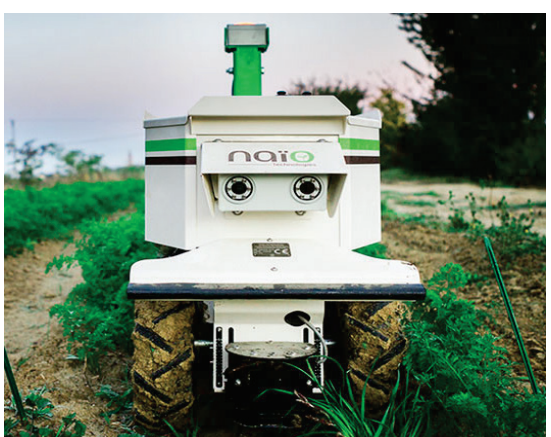

Figure 13 Robot Oz (Source: www.naio-technologies.com [50])

$O z$ is a self-contained robot that has four $110 \mathrm{~W}$ electric motors and four drive wheels. With its use, weed control is significantly easier and simpler, because it has a high degree of precision, and since it works on an electric motor, it does not produce exhaust gases. Dino has been used on a variety of crops such as lettuce, tomatoes, garlic, cabbage, pepper and celery and in a variety of soil conditions. The Dino robot can work between 6 to 8 hours, depending on soil conditions and how many tools it used at the same time. The robots have 
their own navigation system so that it can be used for various types of crops [50].

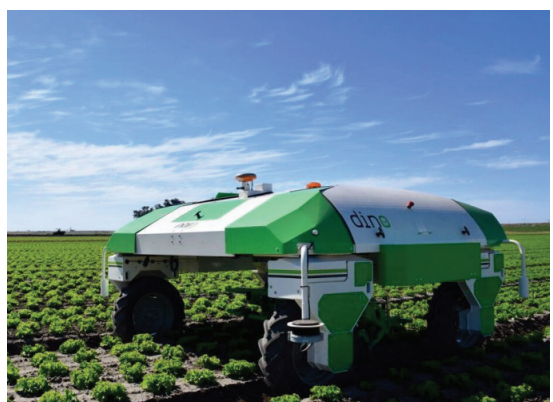

Figure 14 Robot Dino (Source: www.naio-technologies.com [50])

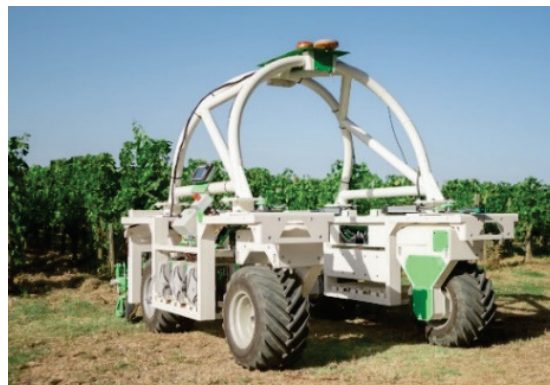

Figure 15 Robot Ted (Source: www.naio-technologies.com [50])

One of the newer smaller weed removal robots is the Tertill. Tertill consists of sensors, weed cutters, solar panel, speakers, robot status indicator, power button, handle, and extreme wheels (Fig. 16).
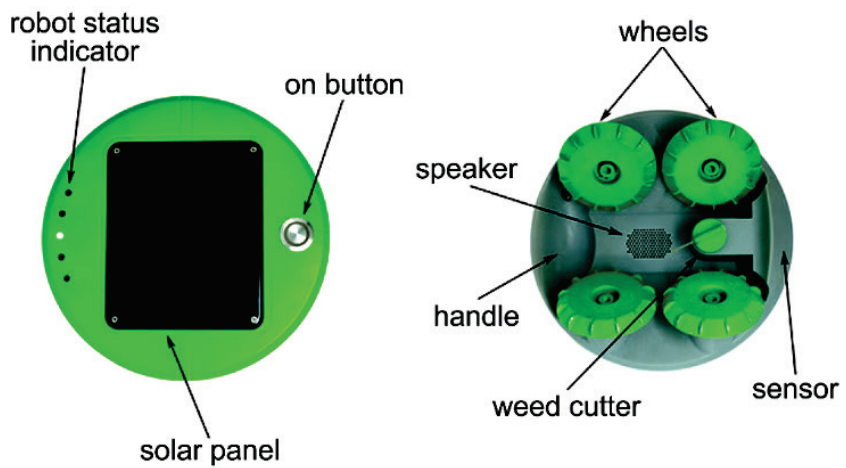

Figure 16 Tertill robot parts (Source: https://tertill.com)

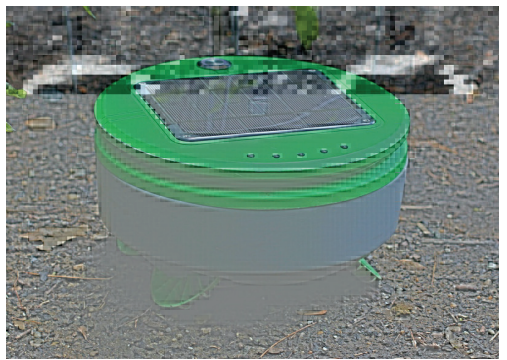

Figure 17 Robot Tertill (Source: https://agtecher.com/product/tertill-robot/)

The working principle is on the simple understanding that plants are long and weeds so anything below 2 inches is a weed. He walks through the field looking for weeds, then cuts them with a rotating nylon cutter. The solar panel and cell use sunlight for electricity and give the necessary power to the robot (Fig. 17) [51].

A pre-commercial electric robot for strawberry harvesting has been developed in Spain. It has own real time AI and integrated color and infrared depth sensors to capture harvest details. From a customizable mobile platform (Fig. 18), 24 robotic manipulators together harvest only those fruits that meet agricultural quality standards [52].

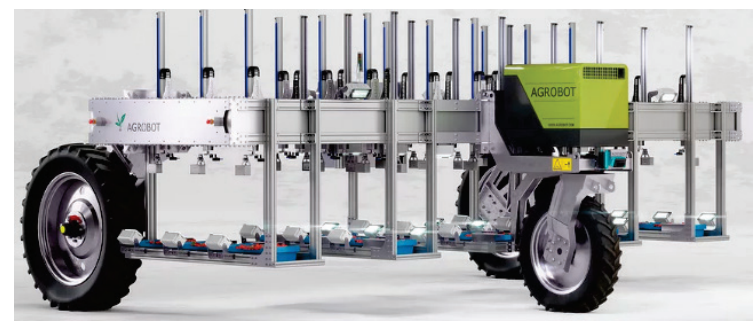

Figure 18 Robot Agrobot (Source: https://www.agrobot.com/e-series/ [52])

For harvesting sweet pepper was developed a prototype robotic harvester Harvey (Fig. 19). Using geometry model to get location, computer algorithms and grippers robot manage and detach pepper from plant [53]. Using very similar working principle a robot Sweeper works (Fig. 20). It has RGB-D camera, algorithm Blob detection, pixel based routine and SSD detector (Single Shot Detector) [54].

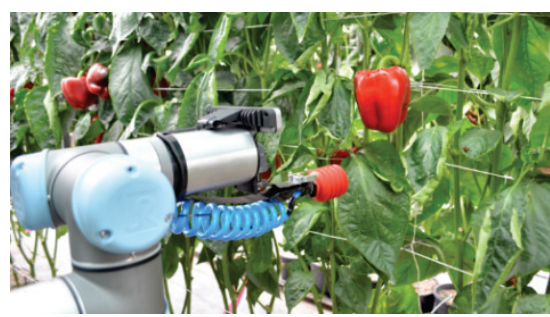

Figure 19 Robot Harvey (Source: https://research.qut.edu.au/future-farming [53])

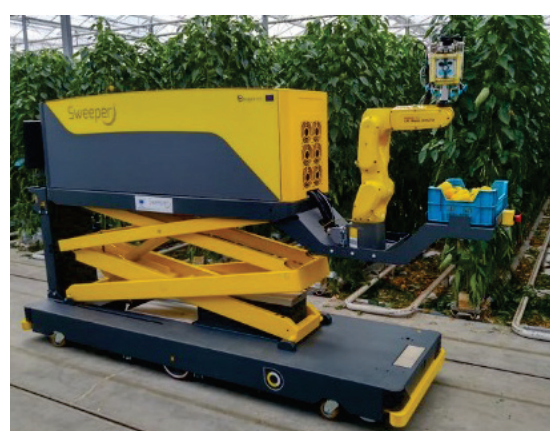

Figure 20 Robot Sweeper (Source: http://www.sweeper-robot.eu/ [54)]

For the plant protection agricultural robot Bonirob has important role. Bonirob (Fig. 21) automates and speeds up analysis. The robot uses video and lidar (3D MEMS lidar, Nippon signal) based positioning as well as satellite navigation to find its way around the fields with RTK. All hardware is connect to main navigation control unit (Fig. 22) $[55,56]$.

For the thai-style dairy farms for milking is designed robot RoboMax (Fig. 23). It goes from cow to cow making 
possible 3 milking a day at regular intervals. Robotic arm cleans the cows teats individually. Laser guided system confirms exact positioning of each teat before attachment teat. Teat cups are attached one bye one and the milk from each quarter is analyzed separately. The milk is monitored to detect contamination providiny precise results on the quantity and quality of milk produced. It has remote access so farmer can be informed on a state and performance of the robot [57].

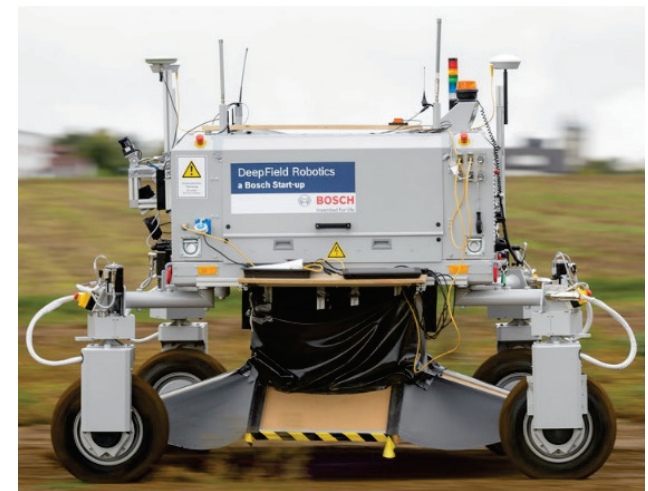

Figure 21 Robot Bonirob (Source: https://linx-global.com [55)]

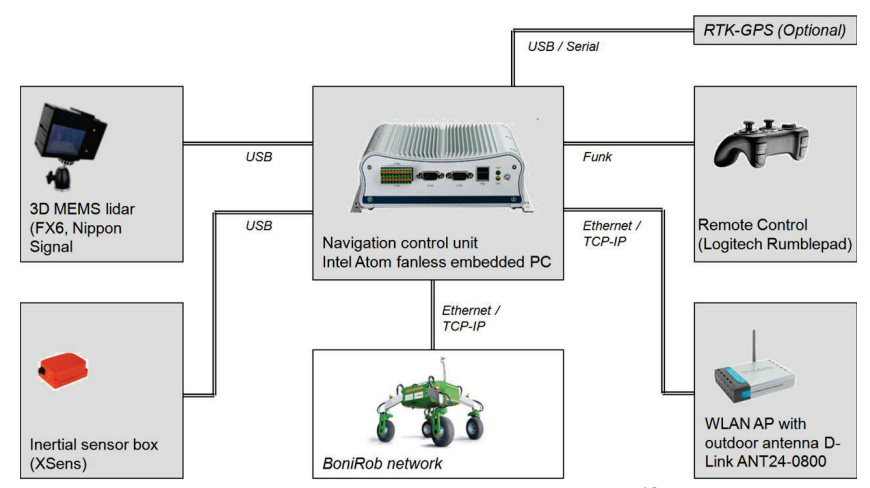

Figure 22 Navigation system hardware Bonirob (Source: https://www.cs.cmu.edu/search/site/robotics?page=1 [56)]

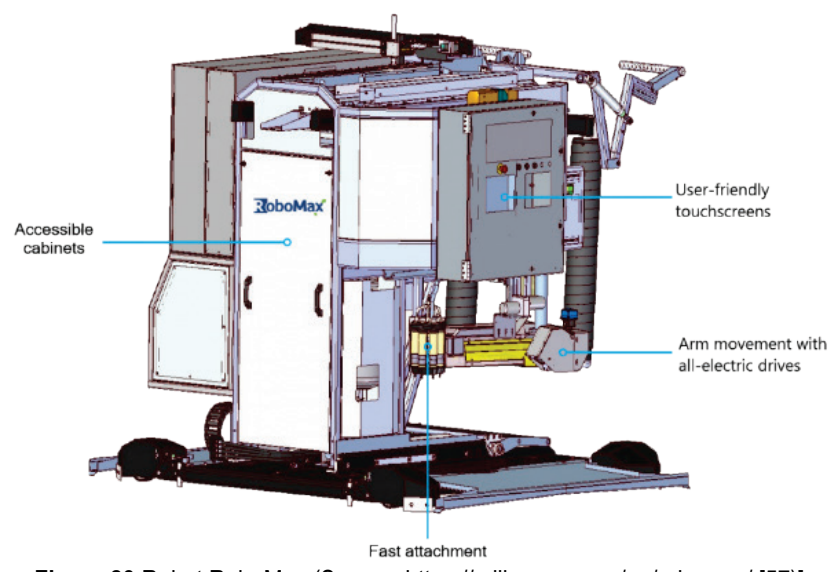

Figure 23 Robot RoboMax (Source: https://milkomax.com/en/robomax/ [57)]

\section{CONCLUSIONS}

The paper depicts a way in which future agricultural production can be automated. Even though the current agrotechnical operations can be performed by people, there is a growing demand for high efficiency in large production areas. The application of robots, robotic systems, and autonomous devices results in a decrease of work operations.

The development of robots has been gradual and the whole concept requires a change in the way of deployment of agricultural machinery, especially the adoption of new ways and approaches.

There are multiple advantages of robotics application in agriculture, such as control and reduction of costs, which have been high until now. Hard and hazardous agricultural tasks justify the use of robots. The rapid development of agricultural robots is based on sensors and the application of artificial intelligence. Furthermore, strenuous work, such as fast and repetitive decision making in fruit picking, can be replaced. A key advantage of robots is that they can perform in conditions in which people cannot ensure good work quality, such as in dark spaces, which can negatively affect quality, productivity, and profit. The use of robots in agriculture fulfils all economic and time management principles that people fail to accomplish.

The main disadvantages of robots are reducing the chances of employment in the industries, farms don't need human labor, robots can't manage in unexpected situations. There is always a chance for machine damages so farms can easily come under chaos. Training costs of employees to work with robots and the installation of machines in the workplace are very high.

\section{REFERENCES}

[1] Zutven, P., Kostic, D., \& Nijmeijer, H. (2009). Modeling, identification and stability of humanoid robots. Master thesis, Eindhoven University of Technology. Retrieved from https://www.tudelft.nl/en/3me/about/departments/biomechani cal-engineering

[2] Billingsley, J., Visala, A., \& Dunn, M. (2008). Robotics in Agriculture and Forestry. In: Siciliano, B. \& Khatib, O. (Eds) Springer Handbook of Robotics. Springer, Berlin, Heidelberg. https://doi.org/10.1007/978-3-540-30301-5_47

[3] Billingsley, J. (2000). Low Cost GPS for the Autonomous Robot Farmhand. Proceedings of the 7th Annual Conference on Mechatronics and Machine Vision in Practice, 119-125. Retrieved from https://eprints.usq.edu.au/5583/

[4] Åstrand, B. \& Baerveldt, A. J. (2002). An agricultural mobile robot with vision-based perception for mechanical weed control. Autonomous robots, 13(1), 21-35. https://doi.org/10.1023/A:1015674004201

[5] Bakker, T., van Asselt K., Bontsema, J., Müller, J., \& van Straten, G. (2011). Autonomous navigation using a robot platform in a sugar beet field. Biosystems Engineering, 109(4), 357-368. Retrieved from https:/www.sciencedirect.com/ science/article/pii/S1537511011000791

[6] Li, M., Imou, K., Wakabayashi, K., \& Yokoyama, S. (2009). Review of research on agricultural vehicle autonomous guidance. International Journal of Agricultural and Biological Engineering, 2(3), 1-16. Retrieved from http://ijabe.org/ index.php/ijabe/article/view/160

[7] Pedersen, S. M., Fountas, S., Have, H., \& Blackmore, B. S. (2006). Agricultural robots-system analysis and economic feasibility. Precision agriculture, 7(4), 295-308. Retrieved 
from https://link.springer.com/article/10.1007/s11119-0069014-9

[8] Stentz, A., Dima, C., Wellington, C., Herman, H., \& Stager, D. (2002). A system for semi-autonomous tractor operations. Autonomous Robots, 13(1), 87-104. Retrieved from https://link.springer.com/article/10.1023/A:1015634322857

[9] Emmi, L., Gonzalez-de-Soto, M., Pajares, G., \& Gonzalez-deSantos, P. (2014). New trends in robotics for agriculture: integration and assessment of a real fleet of robots. The Scientific World Journal, 1-21. Retrieved from https://www.hindawi.com/journals/tswj/2014/404059/

[10] Raguž, R. (2019). Application of robotics in primary school, Pula.

[11] Zutven, P. W. M. (2009). Modeling, identification and stability of humanoid robots with a case study on humanoid robot Tulip, Eindhoven.

[12] Lipnjak, G. (2019). Artificial intelligence and robotics in the function of occupational health protection. The $14^{\text {th }}$ International Conference Management and safety. Retrieved from http://www.european-safety-engineer.org

[13] Lapov Padovan, Z., Kovačević, S., \& Purković, D. (2018). Curriculum development of primary school teaching of robotics, Polytechnica: Journal of Technology Education, 2(1), 7-34. Retrieved from https://hrcak.srce.hr/index.php?show= clanak\&id_clanak_jezik $=305689$

[14] Zimmer, D., Jurišić, M., Plaščak, I., \& Radočaj, D. (2020). Application of robots and robotic systems in agricultural practice. Agriculture in nature and environment protection, 356-361.

[15] Yaghoubi, S., Akbarzadeh, N. A., Bazargani, S. S., Bazargani, S. S., Bamizan, M., \& Asl, M. I. (2013). Autonomous robots for agricultural tasks and farm assignment and future trends in agro robots. International Journal of Mechanical \& Mechatronics Engineering, 13(3), 1-6. Retrieved from http://ijens.org/IJMME\%20Vol\%2013\%20Issue\%2003.html

[16] Adamides, G., Katsanos, C., Constantinou, I., Christou, G., Xenos, M., Hadzilacos, T., \& Edan, Y. (2017). Design and development of a semi-autonomous agricultural vineyard sprayer: Human-robot interaction aspects. Journal of Field Robotics, 34(8), 1407-1426. Retrieved from https://onlinelibrary.wiley.com/doi/full/10.1002/rob.21721

[17] Adamides, G., Katsanos, C., Parmet, Y., Christou, G., Xenos, M., Hadzilacos, T., \& Edan, Y. (2017). HRI usability evaluation of interaction modes for a teleoperated agricultural robotic sprayer. Applied ergonomics, 62, 237-246. Retrieved from https://www.sciencedirect.com/science/article/abs/pii/ S0003687017300674

[18] Moreno, F. A., Cielniak, G., \& Duckett, T. (2013). Evaluation of laser range-finder mapping for agricultural spraying vehicles. Towards Autonomous Robotic Systems, 210-221, Berlin. Retrieved from https://link.springer.com/chapter/ 10.1007/978-3-662-43645-5 22

[19] Oberti, R., Marchi, M., Tirelli, P., Calcante, A., Iriti, M., Hočevar, M., Baur, J., Pfaff, J., Schütz, C., \& Ulbrich, H. (2013). Selective spraying of grapevine's diseases by a modular agricultural robot. Journal of Agricultural Engineering, 44(2). https://doi.org/10.4081/jae.2013.271

[20] Akbar, S. A., Chattopadhyay, S., Elfiky, N. M., \& Kak, A. (2016). A novel benchmark RGBD dataset for dormant apple trees and its application to automatic pruning. In Proceedings of the IEEE conference on computer vision and pattern recognition workshops, 81-88. Retrieved from https://www.cvfoundation.org/openaccess/content_cvpr_2016_workshops/w9 /html/Akbar A Novel Benchmark CVPR 2016 paper.html
[21] Bac, C. W., Henten, E. J., Hemming, J., \& Edan, Y. (2014). Harvesting robots for high-value crops: State-of-the-art review and challenges ahead. Journal of Field Robotics, 31(6), 888911. https://doi.org/10.1002/rob.21525

[22] De-An, Z., Jidong, L., Wei, J., Ying, Z., \& Yu, C. (2011). Design and control of an apple harvesting robot. Biosystems engineering, $110(2), 112-122$. https://doi.org/10.1016/j.biosystemseng.2011.07.005

[23] Nuske, S., Achar, S., Bates, T., Narasimhan, S., \& Singh, S. (2011). Yield estimation in vineyards by visual grape detection, In 2011 IEEE/RSJ International Conference on Intelligent Robots and Systems, 2352-2358. https://doi.org/10.1109//ROS.2011.6095069

[24] Nuske, S., Achar, S., Gupta, K., Narasimhan, S. G., \& Singh, S. (2011). Visual yield estimation in vineyards: Experiments with different varietals and calibration procedures. Retrieved from https://www.researchgate.net/publication/261437679 Visual_Yield_Estimation_in_Vineyards_Experiment

[25] Corollaro, M. L., Aprea, E., Endrizzi, I., Betta, E., Demattè, M. L., Charles, M., Costa, F., Biasioli, F., Corelli, L., \& Gasperia, F. (2014). A combined sensory-instrumental tool for apple quality evaluation. Postharvest Biology and Technology, 96, 135-144. https://doi.org/10.1016/j.postharvbio.2014.05.016

[26] Donis-González, I. R., Guyer, D. E., \& Pease, A. (2016). Postharvest noninvasive assessment of undesirable fibrous tissue in fresh processing carrots using computer tomography images. Journal of Food Engineering, 190, 154-166. https://doi.org/10.1016/j.jfoodeng.2016.06.024

[27] Lunadei, L., Diezma, B., Lleo, L., Ruiz-Garcia, L., Cantalapiedra, S., \& Ruiz-Altisent, M. (2012). Monitoring of fresh-cut spinach leaves through a multi-spectral vision system. Postharvest Biology and Technology, 63(1), 74-84. https://doi.org/10.1016/j.postharvbio.2011.08.004

[28] Munera, S., Besada, C., Blasco, J., Cubero, S., Salvador, A., Talens, P., \& Aleixos, N. (2017). Astringency assessment of persimmon by hyperspectral imaging. Postharvest Biology and Technology, 125, 35-41. https://doi.org/10.1016/j.postharvbio.2016.11.006

[29] Pace, B., Cefola, M., Renna, F., \& Attolico, G. (2011). Relationship between visual appearance and browning as evaluated by image analysis and chemical traits in fresh-cut nectarines. Postharvest Biology and Technology, 61(2-3), 178183. https://doi.org/10.1016/j.postharvbio.2011.03.005

[30] Dael, M., Verboven, P., Dhaene, J., Hoorebeke, L., Sijbers, J., \& Nicolai, B. (2017). Multisensor x-ray inspection of internal defects in horticultural products. Postharvest Biology and Technology, 128, 33-43. https://doi.org/10.1016/j.postharvbio.2017.02.002

[31] Cheein, F. A., Steiner, G., Paina, G. P., \& Carelli, R. (2011). Optimized eif-slam algorithm for precision agriculture mapping based on stems detection. Computers and Electronics in Agriculture, 78(2), 195-207. https://doi.org/10.1016/j.compag.2011.07.007

[32] Lukenda, D. (2015). Economic justification of introducing robots in the production process, Zagreb, 2015. Retrieved from https://eprints.grf.unizg.hr/2430/

[33] Noguchi, N., Will, J., Reid, J., \& Zhang, Q. (2004). Development of a master-slave robot system for farm operations. Computers and Electronics in agriculture, 44(1), 119. https://doi.org/10.1016/j.compag.2004.01.006

[34] Schueller, J. K. (2006). Cigr handbook of agricultural engineering (6), 46. Retrieved from https://cigr.org/node/640

[35] Iida, M., Suguri, M., Uchida, R., Ishibashi, M., Kurita, H., \& Won-Jae, C. (2013). Advanced harvesting system by using a combine robot. IFAC Proceedings Volumes, 46(4), 40-44. 
https://doi.org/10.3182/20130327-3-JP-3017.00012

[36] Bechar, A. \& Vigneault, C. (2016). Agricultural robots for field operations: Concepts and components. Biosystems, Engineering, 149, 94-111. https://doi.org/10.1016/j.biosystemseng.2016.06.014

[37] Zhang, Z., Noguchi, N., Ishii, K., Yang, L., \& Zhang, C. (2013). Development of a robot combine harvester for wheat and paddy harvesting. IFAC Proceedings Volumes, 46(4), 4548. https://doi.org/10.3182/20130327-3-JP-3017.00013

[38] Soffar, H. (2020). Robots in the Workplace advantages, disadvantages and applications, Robotics. Retrieved from https://www.online-sciences.com/robotics/robots-in-theworkplace-advantages-disadvantages-applications/

[39] Nepalla, C. (2018). Agriculture robots the farmers of the future, Rajasthan. Retrieved from https:/www.mpuat.ac.in/ singlePage.php $? \mathrm{id}=60 \&$ type $=\mathrm{SP}$

[40] Jankhaniya, A. (2015). Pest controlling in agriculture by automatic robot, Gandhinagar. Retrieved from https://www.scribd.com/document/409423022/ppt150909043244-lva1-app6891

[41] Canning, J. R., Edwards, D. B., \& Anderson, M. J. (2004): Development of a fuzzy logic controller for autonomous forest path navigation. Transactions of the ASAE, 47(1), 301. https://doi.org/10.13031/2013.15855

[42] Crneković, M. (2016). Industrial and mobile robots. Zagreb. (in Croatian)

[43] Font, D., Pallejà, T., Tresanchez, M., Runcan, D., Moreno, J., Martínez, D., Teixidó, M., \& Palacín, J. (2014). A proposal for automatic fruit harvesting by combining a low cost stereovision camera and a robotic arm. Sensors, 14(7), 11557-11579. https://doi.org/10.3390/s140711557

[44] http://robotics.ee.pusan.ac.kr/ (Accessed: 17.02.2021.)

[45] Chalwa, V. N. \& Gundagi, S. S. (2014). Mechatronics Based Remote Controlled Agricultural Robot. International Journal of Emerging Trends in Engineering Research, 2(7). Retrieved from warse.org/pdfs/2014/ijeter01272014.pdf

[46] https://www.istockphoto.com/illustrations/smart-farm (Accessed: 17.02.2021)

[47] https://www.ecorobotix.com/en/autonomous-robot-weeder/ (Accessed: 17.02.2021)

[48] http://web.tuat.ac.jp/ toyama/research_assistancesuitE.html (Accessed: 17.02.2021)

[49] Milić, V. (2015). Minimax optimal control of nonlinear dynamical systems, Zagreb. Retrieved from https://urn.nsk.hr/urn:nbn:hr:235:830309

[50] https://www.naio-technologies.com/en/agricultural-equipment (Accessed: 17.02.2021)

[51] https://tertill.com/pages/tertill-reviews (Accessed: 17.02.2021)

[52] https://www.agrobot.com/e-series (Accessed: 27.02.2021)

[53] https://research.qut.edu.au/future-farming (Accessed: 27.02.2021)

[54] http://www.sweeper-robot.eu/ (Accessed: 27.02.2021)

[55] https://linx-global.com/blog/2017/10/17/an-agricultural-weedkilling-robot-that-doesnt-use-chemicals (Accessed: 27.02.2021)

[56] Biber, P., Weiss, U., Dorna, M., \& Albert, A. (2012). Navigation System of the Autonomous Agricultural Robot "BoniRob". Proceedings of the 2012 IROS Workshop on Agricultural Robotics: Enabling Safe, Efficient, Affordable Robots for Food Production. https://www.cs.cmu.edu/ mbergerm/ agrobotics2012/01Biber.pdf (Accessed: 27.02.2021)

[57] https://milkomax.com/en/robomax/ (Accessed: 27.02.2021)

\author{
Authors' contacts: \\ Domagoj Zimmer, PhD, Assistant \\ (Corresponding author) \\ Faculty of Agrobiotechnical Sciences Osijek, \\ Vladimira Preloga 1, 31000 Osijek, Croatia \\ dzimmer@fazos.hr \\ Mladen Jurišić, PhD, Full Professor \\ Faculty of Agrobiotechnical Sciences Osijek, \\ Vladimira Preloga 1, 31000 Osijek, Croatia \\ mjurisic@fazos.hr
}

Ivan Plaščak, PhD, Assistant Professor

Faculty of Agrobiotechnical Sciences Osijek, Vladimira Preloga 1, 31000 Osijek, Croatia iplascak@fazos.hr

Željko Barač, PhD, Assistant

Faculty of Agrobiotechnical Sciences Osijek, Vladimira Preloga 1, 31000 Osijek, Croatia

zbarac@fazos.hr

Dorijan Radočaj, MSc, Assistant

Faculty of Agrobiotechnical Sciences Osijek, Vladimira Preloga 1, 31000 Osijek, Croatia dradocaj@fazos.hr 